\title{
Loess as a Quaternary paleoenvironmental indicator
}

\author{
Daniel R. Muhs', M.A. Prins ${ }^{2}$ and B. Machalett ${ }^{3}$
}

\begin{abstract}
Loess (aeolian silt) is widespread in Eurasia and the Americas. Paleowind direction and wind strength can be reconstructed from spatial and temporal trends of loess thickness and particle size. Fossil land snails in loess can reveal much about past climate and vegetation.
\end{abstract}

Loess is aeolian sediment that is dominated by silt-sized particles. Unlike either coarser dune sand or finer-grained, long-rangetransported dust, loess is relatively poorly sorted, reflecting a combination of transport processes, including saltation, low suspension, and high suspension. Loess can be readily identified in the field; deposits range in thickness from a few centimeters to many tens of meters, and are found over large areas of Eurasia, South and North America (Fig. 1), and smaller areas of New Zealand, Australia, Africa and the Middle East. Loess covers approximately $10 \%$ of the Earth's land surface and is therefore one of the most important terrestrial archives of paleoenvironmental change during the Quaternary. In many regions, loess sections consist of deposits of mostly unaltered sediment with intercalated paleosols. Paleosols represent periods of landscape stability when loess deposition ceased altogether, or at least slowed significantly. Loess can be dated directly using luminescence, radiocarbon, and amino acid geochronology methods.

\section{Paleoclimatic interpretation}

Loess property changes yield clues about the prevailing paleowinds during deposition. Thickness, particle size, and carbonate content, in general, decrease away from sources (e.g. Muhs 2013; Muhs et al. 2014). Thus, reduction in sediment load downwind from a source can be inferred from decreases in loess thickness. Paleowind direction and intensity can also be determined from the decrease in mean particle size away from a source, reflecting a winnowing of the coarse load in regions proximal to the dust source. Here we present some recent examples where paleoclimatic conditions in the Quaternary were inferred from loess deposits.

\section{Determining source areas}

A good example of the spatial variability of loess properties that can be used to infer paleowinds comes from the Chinese Loess Plateau region (Fig. 1a). Prins and Vriend (2007) conducted detailed measurements of loess stratigraphy, loess unit thicknesses, and particle size in a transect of loess sections across this region. Their results indicate that loess dating to the last glacial period, 25-12 ka, referred to as the "L1-1" unit, shows a systematic decrease in thickness and an increase in the abundance of fine silt (modal size of $\sim 22 \mu \mathrm{m}$ ) from north to south (Fig. 2a). This implies that loess source areas during the last glacial period lay to the north of the Chinese Loess Plateau, in the desert basins situated to the north and northwest of the region, which is consistent with various previous findings (see Muhs 2013; Muhs et al. 2014). Northerly or northwesterly paleowinds inferred from these observations indicate longer residence of the Siberian and Mongolian high-pressure systems (dominant in winter today) during the last glacial period and a shorter East Asian and Indian summer monsoon season.

\section{Changes in wind strength}

Changes in wind strength over time can be inferred from the particle size spectrum through a loess section. A number of researchers have used the ratio of coarseto-fine silt as an indicator of wind strength at single sites over time in loess sections of Asia, Europe, and North America. Higher abundances of coarse silt imply stronger winds, which are capable of entraining and transporting coarser particles. Machalett et al. (2008) provide an example from a thick loess section in Kazakhstan, Central Asia (Fig. 2b). Glacial periods are recorded as thick, relatively unaltered sections of loess, whereas interglacial and interstadial periods are recorded as paleosols. The loess of Kazakhstan is, however, an excellent example of the kind of depositional system where aeolian particle transport and deposition do not "turn off" completely during interglacial and interstadial periods. Instead, deposition of the very fine-grained loess particles continued throughout the interglacials, but pedogenesis proceeded at rates greater than the loess sedimentation. The continued loess accumulation implies that loess source areas still existed during interglacial or interstadial periods, but wind strength was too low to transport coarse-silt-sized
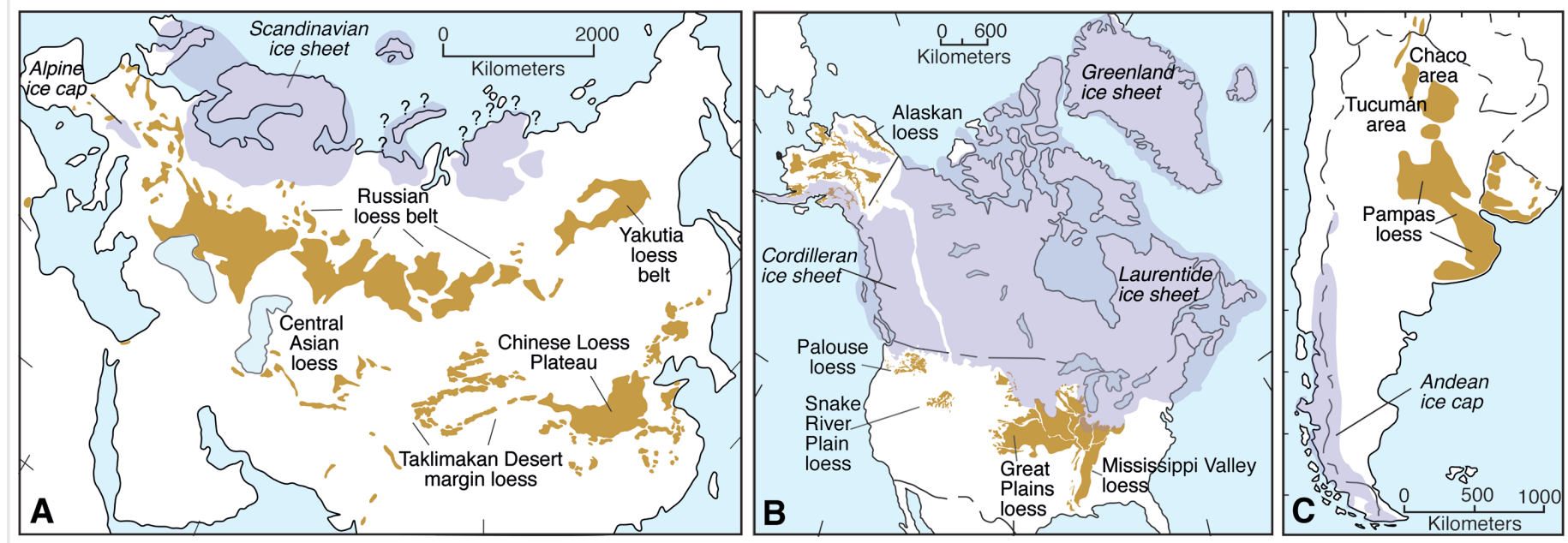

Figure 1: Distribution of loess in (A) Eurasia, (B) North America and (C) South America. Redrawn from Muhs (2013) and Muhs et al. (2014), and sources therein. 

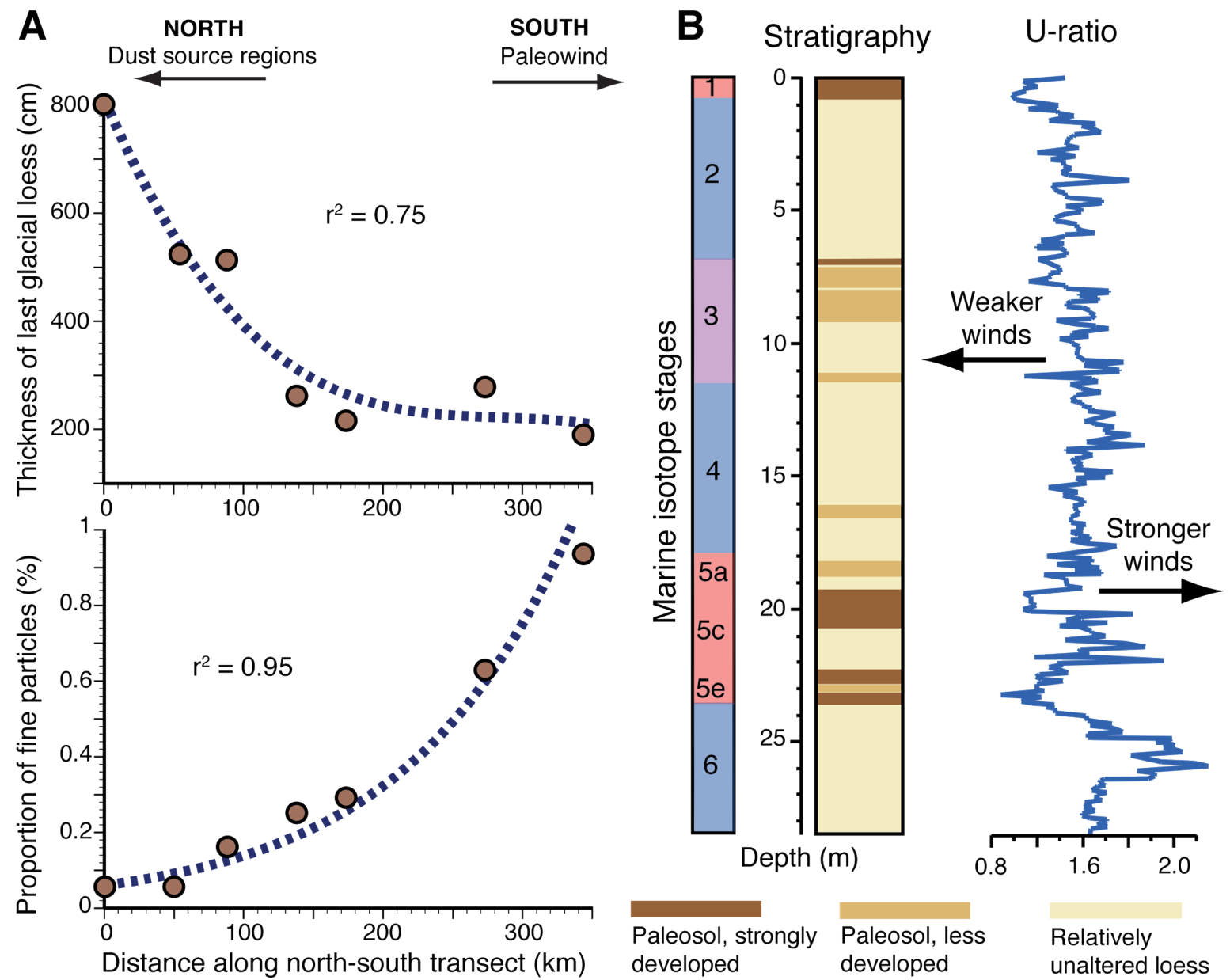

Figure 2: (A) Trends in thickness (upper plot) and abundance of fine silt particles (modal size of $\sim 22 \mu \mathrm{m}$; lower plot) shown as a function of distance along a north-south transect in the Loess Plateau region of China, for last-glacial-aged loess (unit L1-1 in the Chinese loess stratigraphic system). Redrawn from data in Prins and Vriend (2007). (B) Stratigraphy of loess deposited during the past two glacial periods and ratio of coarse-plus-medium silt to fine silt (the "U-ratio") at a thick loess section at Remisowka, Kazakhstan. Note that while loess sedimentation occurs at a greatly diminished rate during interglacial or interstadial periods, allowing soil formation, it does not cease completely. Redrawn from data in Machalett et al. (2008).

particles. This variation in wind strength over time is documented by changes in the "U-ratio", a measure of coarse-plus-medium silt to fine silt (Fig. 2b). During the last glacial period (marine isotope stage or MIS 2 and 4 ) and the penultimate glacial period (MIS 6), high U-ratios indicate strong winds capable of transporting coarse particles, similar to modern winters. Conversely, in interglacial and interstadial periods (MIS 1, 3, and 5) aeolian silt was deposited concurrently with pedogenesis, but was dominated by fine-siltsized particles, resulting in lower U-ratios. This interglacial pattern is due to weaker winds under a different synoptic-scale atmospheric circulation pattern, much more like that during modern summers.

\section{Land snail fossils}

Loess lacks many of the Quaternary paleoecological indicators commonly used in lacustrine or marine sediments, such as pollen, diatoms, ostracodes, radiolaria, or foraminifera. Furthermore, it is rare for mammalian fossils to be preserved in loess, although the deposits in Alaska (USA) and Siberia (Russia) are important exceptions to this generalization. Fortunately, it is common for the shells of land snails to be preserved in-situ in loess, most abundantly in China, Europe, and North America. Most of these snails are extant species, and their modern zoogeography is reasonably well established. Thus, it is possible to infer past climates during the times of loess deposition through the identification of extralimital taxa, i.e. those species that do not currently live in a locality but can be found there as fossils. Many of the land snail shells can be radiocarbon dated (Pigati et al. 2013). In North America, loess deposited during the last glacial period revealed a number of extralimital species of land snail fossils. For example, in the Great Plains region, the upper part of last-glacial loess contains several boreal (extralimital northern) or Cordilleran (western mountain) species of snails that do not live in the region today. The presence of these northern-forest and mountain-forest species implies a much cooler glacial climate with forest vegetation, as opposed to the temperate grassland dominating the region today.

\section{Conclusions}

Loess is found over large areas of Europe, Asia, South America, and North America. Loess has the distinct advantages over other Quaternary sediments for documenting climate change in that it provides a direct record of atmospheric circulation. It can be dated directly by luminescence, radiocarbon, and amino acid geochronology methods. The direction and strength of paleowinds can be reconstructed from spatial and temporal trends of loess thickness and particle size. Paleosols are common in loess and represent periods of little or no loess deposition. Fossil land snails that are often well-preserved in loess can provide paleontological information on past climate and vegetation.

\section{ACKNOWLEDGEMENTS}

We thank the guest editors for inviting us to contribute this short piece and Margaret Berry, Randy Schumann, and Janet Slate for helpful reviews.

\section{AFFILIATIONS}

${ }^{1}$ US Geological Survey, Denver, USA

${ }^{2}$ Faculty of Earth and Life Sciences, VU University Amsterdam, the Netherlands

Institute of Geography, Humboldt-Universität zu Berlin, Germany and Department of Natural and Applied Sciences, Bentley University, Waltham, USA

\section{CONTACT}

Daniel R. Muhs: dmuhs@usgs.gov

\section{REFERENCES}

Machalett B et al. (2008) Geochem Geophys Geosys 9, doi:10.1029/2007GC001938

Muhs DR (2013) Treatise Geomorph 11: 149-183

Muhs DR et al. (2014) In: Knippertz P, Stuut J-B W (Eds) Mineral Dust - A Key Player in the Earth System. Springer, 51-74

Pigati JS et al. (2013) Quat Sci Rev 76: 114-128

Prins MA, Vriend M (2007) Geochem Geophys Geosys 8, doi:10.1029/2006GC001563 